\title{
Effects of Group-Based Acceptance and Commitment Therapy on the Adolescent's Emotional Regulation and Mood States
}

*Barzegari Dehaj. A ${ }^{1}$
jahandari. P2
Hossein Sabet. F3
Borjali. A4
1- ('Corresponding Author)
MSc in Clinical Psychology,
Allameh Tabataba'i University,
Tehran, Iran.
Email: Brzegar1991@yahoo.com
2- MSc in Counseling, Research
Institute for Military Medicine
Science and Technology,
Aja University of Science
Sciences, Iran, Tehran.
3- Assistant Professor,
Department of Clinical
Psychology, School of
Psychology and Education,
University of Allameh
Tabataba'i, Tehran, Iran.
4- Associate professor,
Department of Clinical
psychology, School of
psychology and Education,
University of Allameh
Tabataba'i, Tehran, Iran.

\begin{abstract}
Introduction: Inefficient emotion regulation and negative mood states play significant roles in adolescent's neuroses.
\end{abstract}

Objective: The current study aimed at investigating the effects of group-based acceptance and commitment therapy on the adolescent's emotional regulation and mood states.

Materials and Methods: The present quasi-experimental study was conducted on all adolescents of Sadiq-al-Vaed socio-cultural Center of Tehran, Iran. The subjects included 26 adolescents selected by convenience sampling. The experimental group received acceptance and commitment therapy in eight 75-minute sessions. For data analysis, SPSS software version 20 was employed using repeated measures tests at 0.05 significance level.

Results: According to the obtained results, a significant decrease was observed in suppression $(\mathrm{P}=0.01)$, depression $(\mathrm{P}=0.001)$, tension $(\mathrm{P}=0.001)$, confusion $(\mathrm{P}=0.001)$, and fatigue $(\mathrm{P}=0.02)$ subscales after psychotherapy in post-test and follow-up. The effects lasted in the two-month follow-up period $(\mathrm{P}>0.05)$.

Discussion and Conclusion: According to the study findings, this therapy method can improve emotion regulation and mood state in adolescents and can be used as an effective intervention.

Keywords: Acceptance and Commitment Therapy, Emotion Regulation, Mood States. 


\section{تأثير آموزش كروهى درمان مبتنى بر يذير ش و تعهد بر تنظيم هيجان و حالتهاى خلقى نوجوانان}

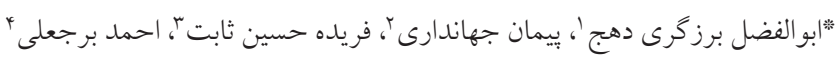

جكيده

مقدمه: تنظيم هيجان ناكار آمد و حالتهاى خلق منفى نقش مهمى در اختلالات روانى نوجوانان دارند. هدف: يزوهش حاضر با هدف بررسى تأثير آموزش كروهى درمان مبتنى بر پذيرش و تعهد بر تنظيم هيجان و حالتهاى خلقى نوجوانان به انجام رسيد. مواد و روشها: اين يزوهش به شيوه نيمه تجربى صورت گرفت. جامعه آمارى مطالعه، كليه نوجوانان عضو كانون فرهنكى اجتماعى صادق الوعد تهران بودند. حجم نمونه با روش نمونهَيرى در دسترس، عץ نفر تعيين شد. براى ارزيابى متغيرها از يرسشنامهاى تنظيم هيجان و حالتهاى خلقى استفاده شد. نوجوانان كروه آزمون به مدت 1 جلسه VD دقيقهاى تحت درمان مبتنى بر يذيرش و تعهد قرار كرفتند. براى آناليز دادها از نرمافزار SPSS نسخه • بَ و آزمون آمارى تحليل واريانس با اندازهيرى مكرر استفاده شد.

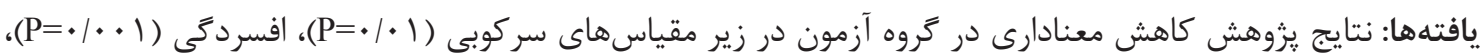

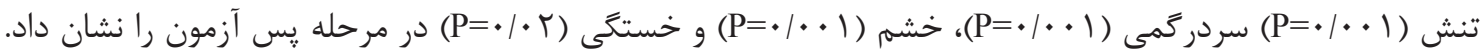

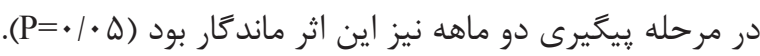
بحث و نتيجه كيرى: با توجه به يافتههاى اين يزوهش، اين شيوه درمانى مى تواند، باعث بهبود تنظيم هيجان و حالتهاى

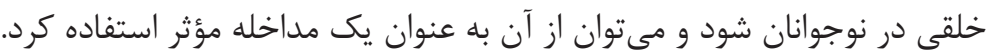
كلمات كليدى: تنظيم هيجان، حالتهاى خلقى، درمان مبتنى بر بذيرش و تعهد.

اختلالاتى همجون اختلال شخصيت مرزى، افسردىى اساسى، دوقطبى، اضطراب تعميميافته، اضطراب اجتماعى، اختلالات خوردن و اختلالات سوءمصرف مواد و الكل ازجمله اختلالاتى هستند كه نقش دشوارى نظمبخشى هيجانى در آنها تائيد شده

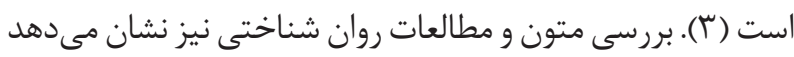
كه تنظيم هيجان، عامل مهمى در تعيين سلامتى و داشتن عملكرد موفق در تعاملات اجتماعى است (ع). به طور كلى، تنظيم هيجان
سالهاى نوجوانى يكى از يراسترسترين مراحل زندگى محسوب مىشود. در اين دوره رشدى، نوجوانان تغييرات بسيار سريع جسمانى و روانشناختى را تجربه مىكنند (1). اين تغييرات موقعيتهاى عاطفى را فراهم مىسازد كه مىتواند به افزايش تجربههاى عاطفى منفى و بى ثباتى هيجانى در نوجوانان منجر

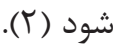
در سال هاى اخير تنظيم هيجان به عنوان يك فرايند هستهاى در 
كه كاركردهاى سازگارانهاى دارند، نقش تخريب گرانهاى بازى

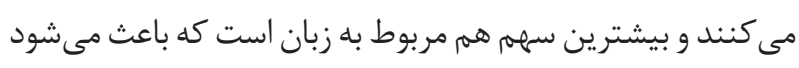

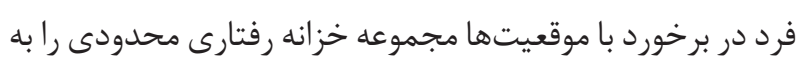

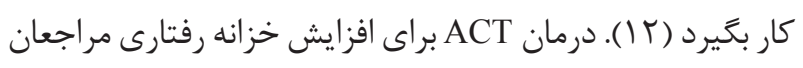

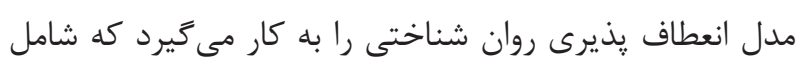

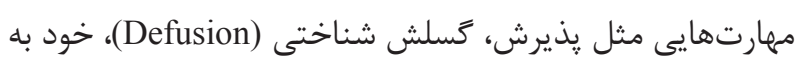
عنوان زمينه (Self as Context) و ذهن آكاهي (Mindfulness)

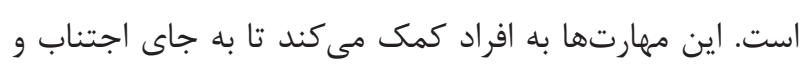

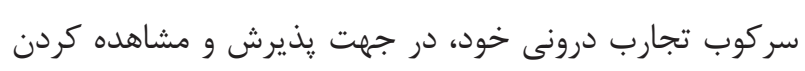

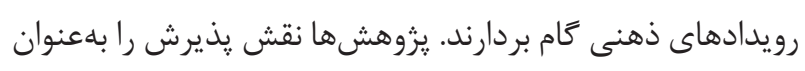
راهبرد مؤثر بر خلق منفى و افسرده تائيد كرده اند (با ا). رابينز

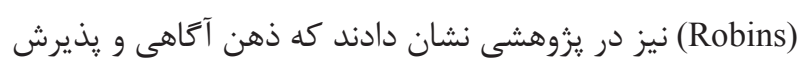

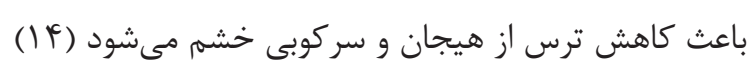

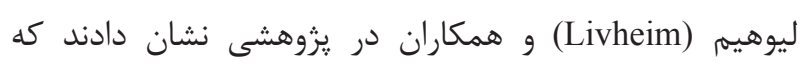

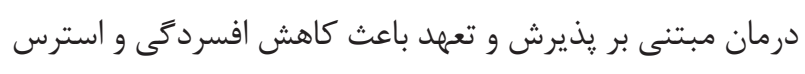

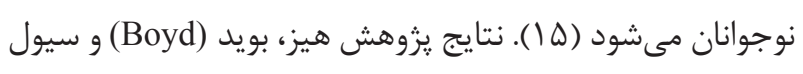

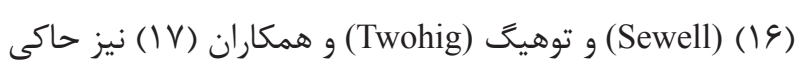
از اثربخشى ACT در بهبود افسردگى نوجوانان بود. حيدرى و

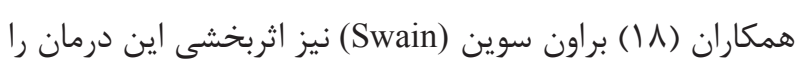

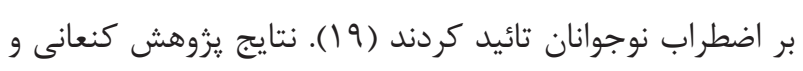

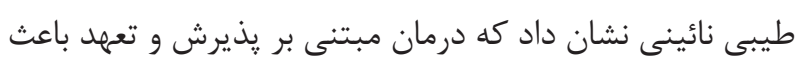

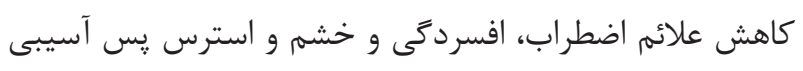
در نوجوانان مىشود. همجنين نتايج يزوهش كلسون (Kelson)

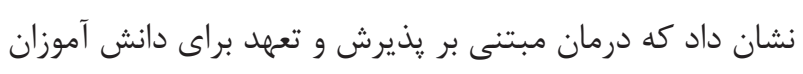
داراى فوبى اجتماعى قابليت كاربرد داشته و مى دوتواند بلهعنوان يك مداخلهى روانشناختى در كنار ساير مداخلات مورد استفاده

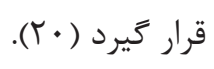

مرور ادبيات يزوهش نشان مىدهد كه اثربخشى اين درمان بر اختلال خلقى (افسردگى) و اختلالات اضطرابى (اضطر اب فراخير،

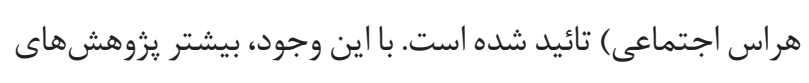

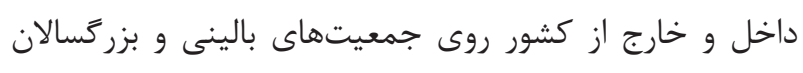

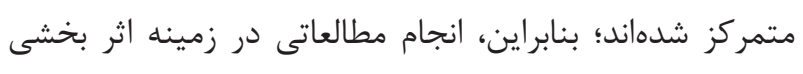
مداخلات روانشناختى جهت اصلاح راهبردهاى تنظيم هيجانى و مناني مشكلات خلقى نوجوانان مىتواند در جهت يِيشخيرى از اختلالات
شامل تغييراتى در يويايىهاى هيجان (ه) يا نهفتتىى، زمان شروع،

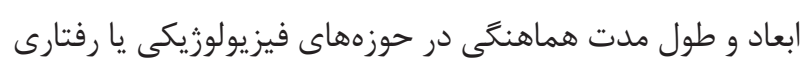
مىشود. مدل فرايندى تنظيم هيجان، دو راهبرد ارزيابى مجدد مداد

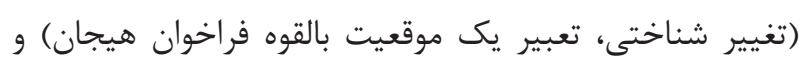

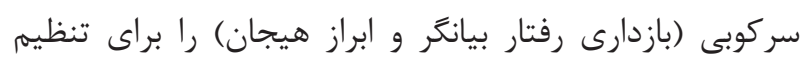

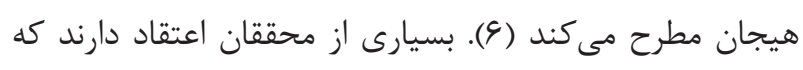

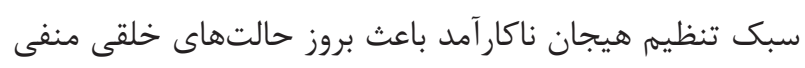

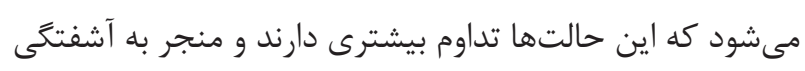
فرد مىشوند. حالتهاى خلقى بيشتر بلهصورت ذهنى احساس مىشوند و بر خلاف هيجان كه بيامدهاى رفتارى دارد، بيشتر

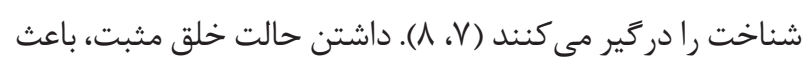

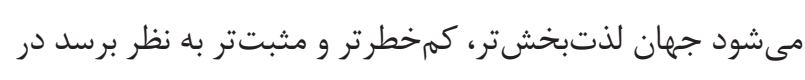

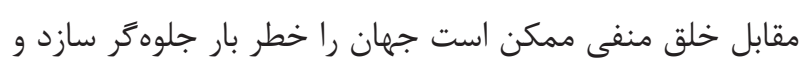

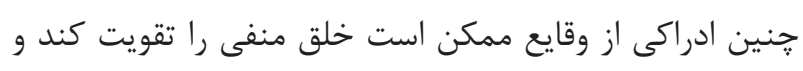

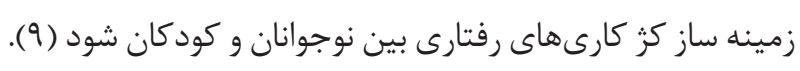

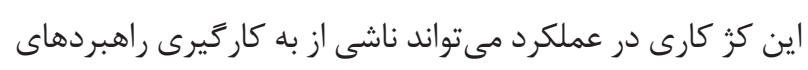

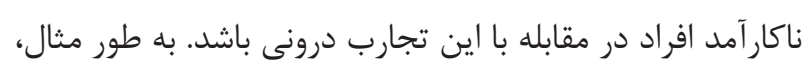

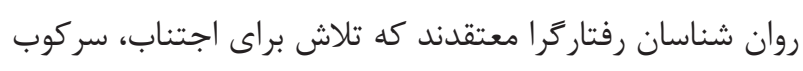
يا حذف رويدادهاى ذهنى، مانند خلق و هيجان ها ممكن است در

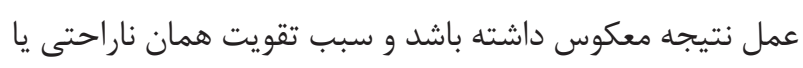
آزردَى خاطرى شود كه فرد آن را تجربه مى كند (• (1).

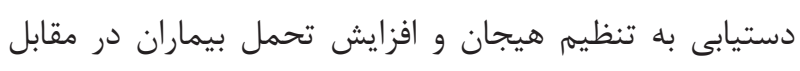

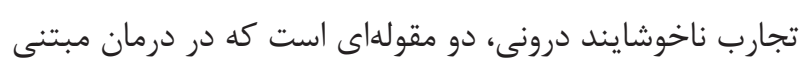

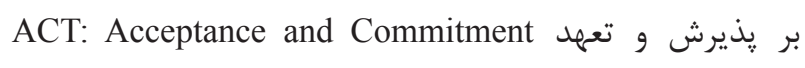

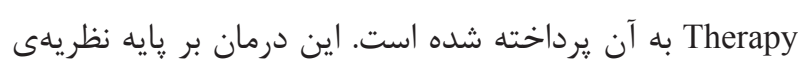

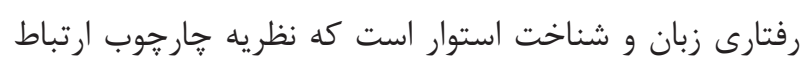
نام دارد. مطابق با اين نظريه، علت (Relational Frame Theory) اصلى مشكلات ناشى از هيجان، جگَونكى نقش داشتن ماهيت

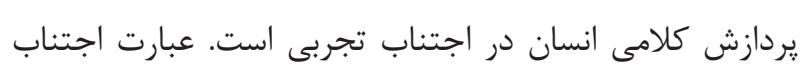

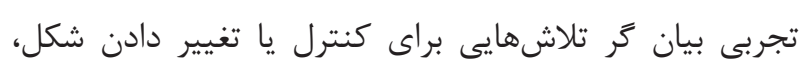

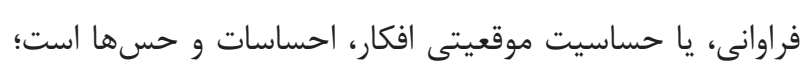
حتى اكر اين امر سبب آسيب رفتارى شود (1) (1). ديدكاه

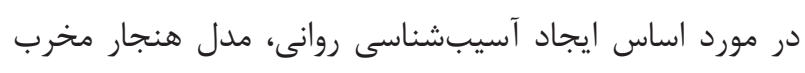

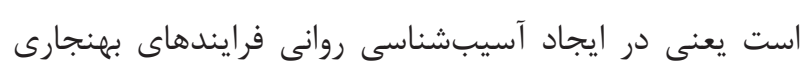


در سال r. • ب تهيه شده است. مقياس فوق از • ا كويه تشكيل شده است كه داراى دو خرده مقياس ارزيابى مجدد (4 كوية) و و

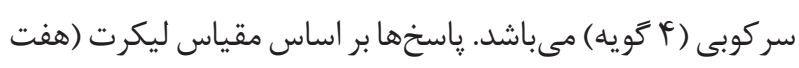

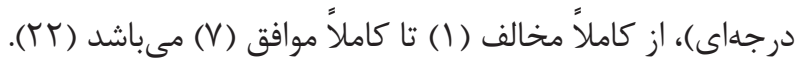

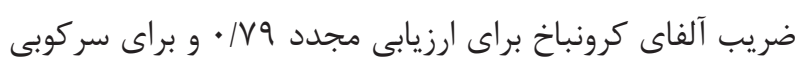

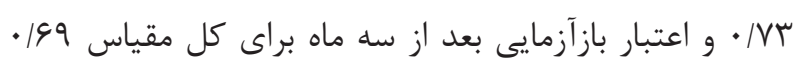
كزارش شده است. ضرايب همبستگى ارزيابى مجدد با مقياس

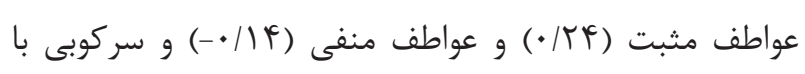

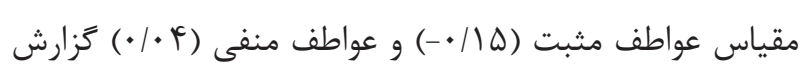

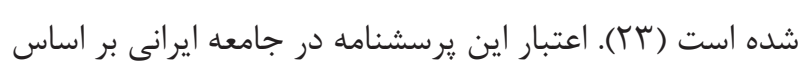

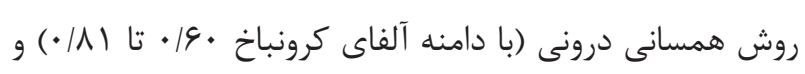

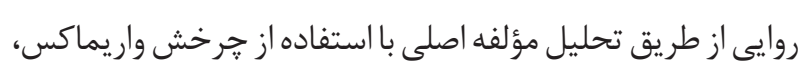

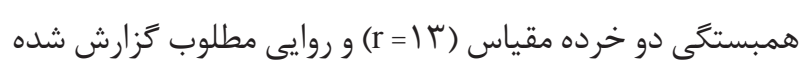

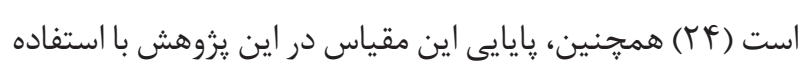

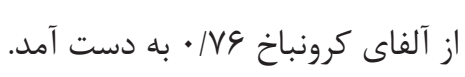
مقياس حالتهاى خلقى: اين مقياس توسطترى (Terry) و همكاران

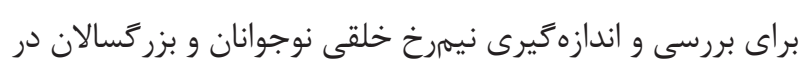

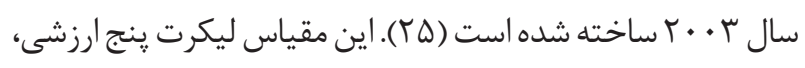

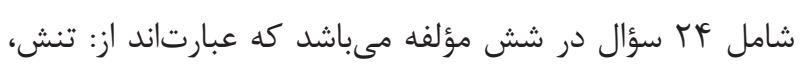

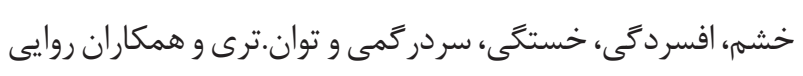

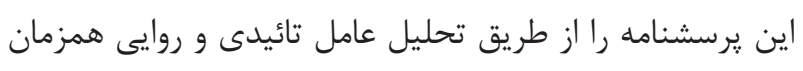
با ٍرسشنامه نيمرخ حالتهاى خلقى موركان (POMS)، مورد

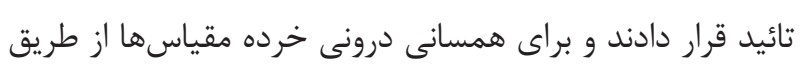

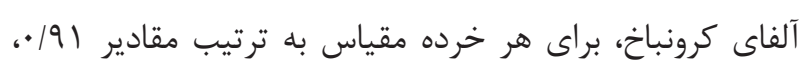

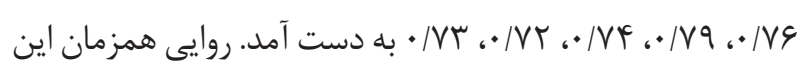
يرسشنامه با يرسشنامه حالتهاى خلقى (POMS) مور كان، توسط

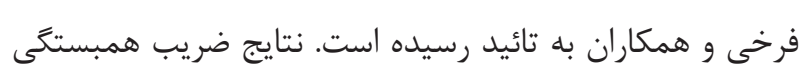

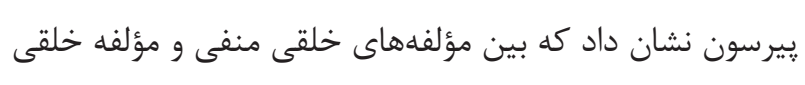

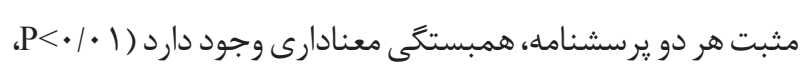

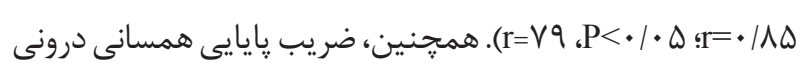

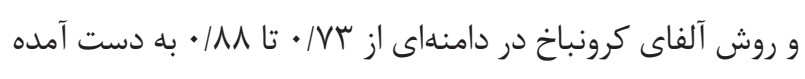

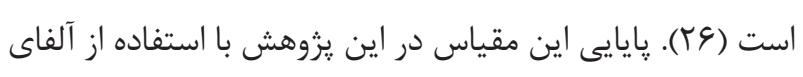

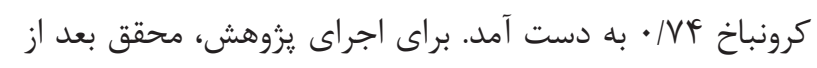

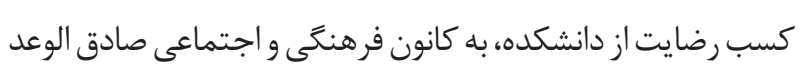

روانى در بزر كَالى راهَشا باشد؛ بنابراين يزروهش حاضر با هدف

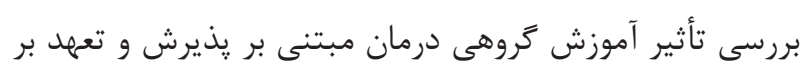
تنظيم هيجان و حالتهاى خلقى نوجوانان به انجام رسيد.

\section{مواد و روشها}

يروهش حاضر به صورت نيمه تجربى با بيش آزمون - پِسآزمون

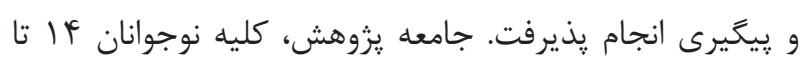
r r.

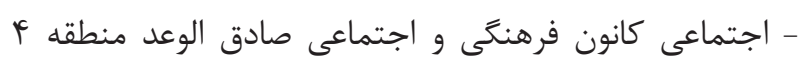

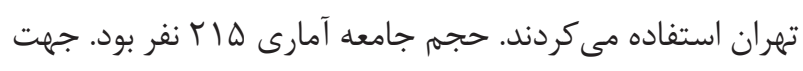

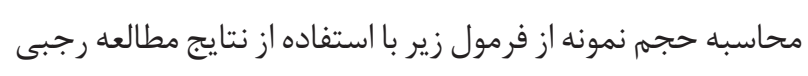

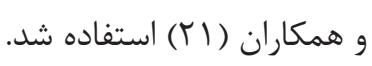

$$
n=\frac{\left(\sigma^{r}+\sigma^{r}\right)+\left(Z_{1-\frac{\alpha}{r}}+Z_{1-\beta}\right)}{\delta^{r}}
$$

$n=\frac{\left.(V / \Lambda)^{r}+r / r^{r}\right)+\left((/ 9 \varphi+1 / r \Lambda)^{r}\right.}{V / Q^{r}}=1 r / r$

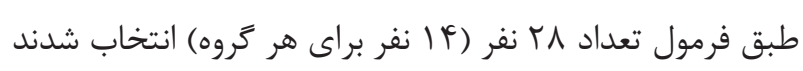

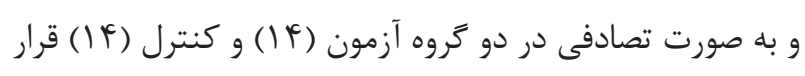

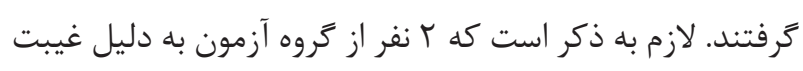

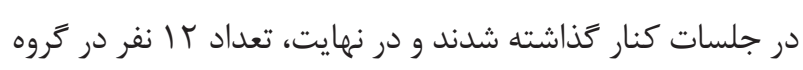

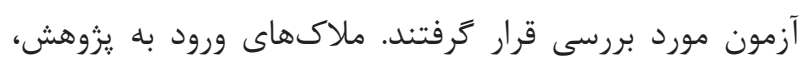

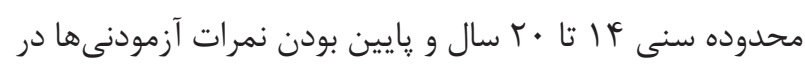

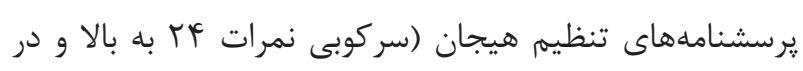

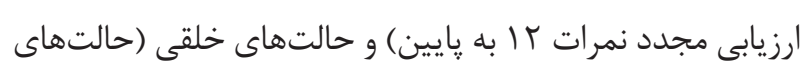

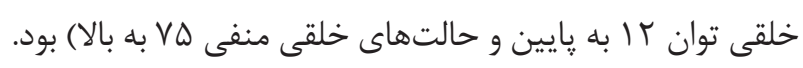

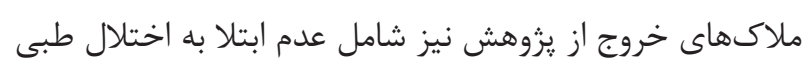
مزمن، غيبت بيش از دو جلسه در فرايند آموزش، استفاده نوجوان

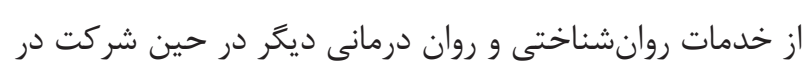

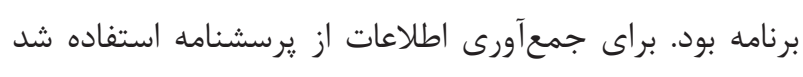

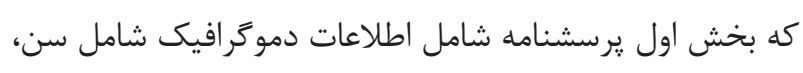
جنس و پايه تحصيلى بود. يرسشنامه تنظيم هيجان: اين :رسشنامه توسط كراس (Gross)

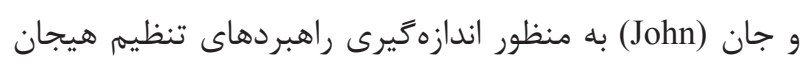


بحيرند. خلاصه جلسات درمان در جدول شماره ا ارائه شده است.

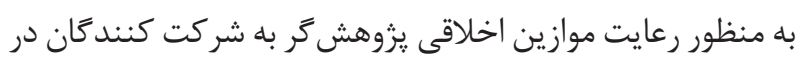
يزوهش اطمينان دادند كه: شركت در يزوهش و ادامهى حضور

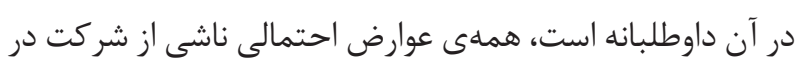

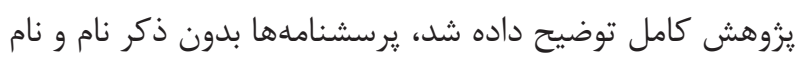

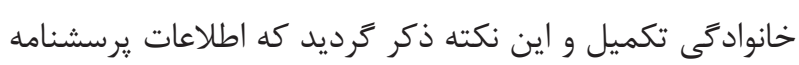

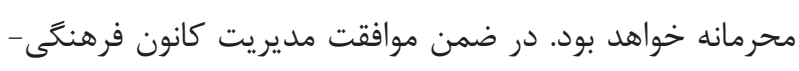
آموزشى صادق الوعد و اولياء شركت كنند

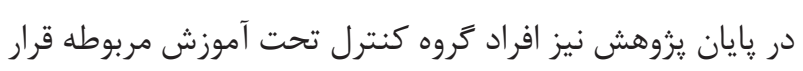

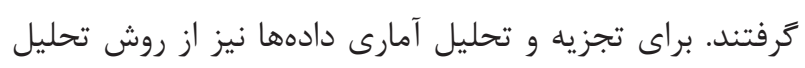

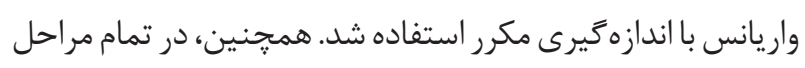
تحليل از نرمافزار SPSS نسخه • ب استفاده شد.

يافتهها

ميانگين سنى افراد شركت كننده در كروه آزمون 1 ا سال با انحراف

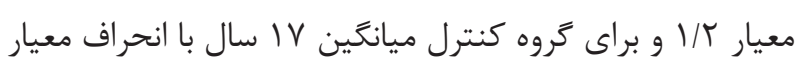

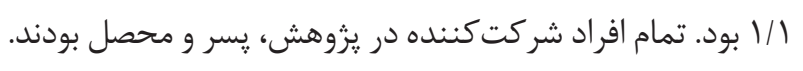

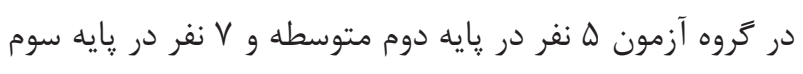

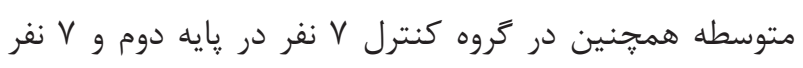

مر اجع كرد و يرسشنامههاى حالتهاى خلقى و تنظيمى هيجان رادر

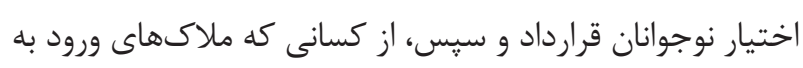
يزوهش را داشتند، دعوت به همكارى شد. در نهايت، افراد بلهصورت تصادفى در دو گروه آزمون و كنترل قرار كرفتند.

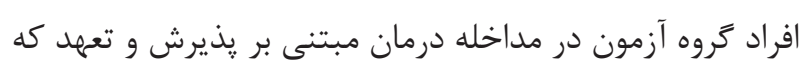

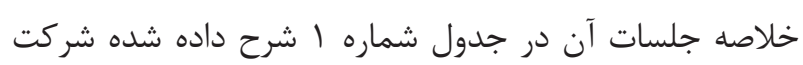

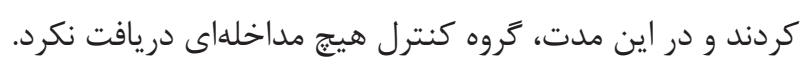

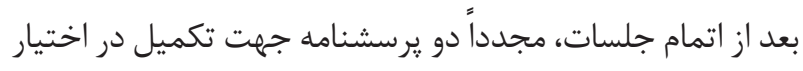

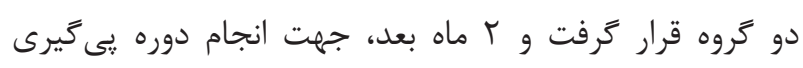
يرسشنامهها در اختيار گروه نمونه قرار داده شد.

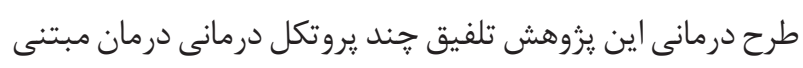

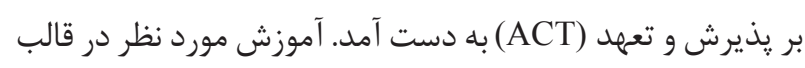

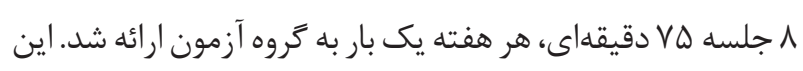

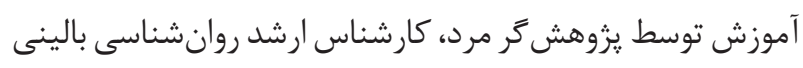

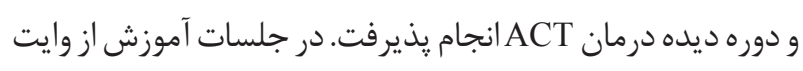

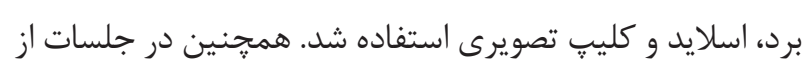
تمرين هاى رفتارى به شكل ايفاى نقش و كفتتو در مورد مطالب

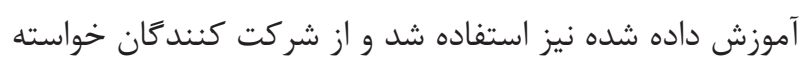

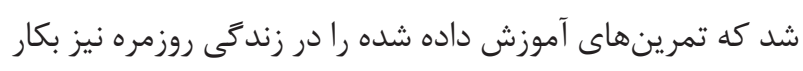

جدول ا- خلاصه جلسات آموزش مبتنى بر يذيرش و تعهد

\begin{tabular}{|c|c|}
\hline محتوا & جلسات \\
\hline افكار منفاخى ماهيت هيجان، افكار و عمل، ايجاد درماندگى خلاقانه (ناميد كردن نوجوان از كنترل كردن تجارب درونى خود مانند & سه اول \\
\hline براى ذهن عادت كردن به اجتى & سسه دوم \\
\hline تغيير دادن ارتباط مراجع با تجارب درونى، اجراى تمرينات ذهن آكَاهى و گسلش شناختى (Defusion) & 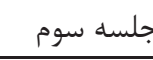 \\
\hline تميز و كثيف دادن مهارت ذهن آكاهى و گَلش شناختى، تمرين آكاهى از احساسات همراه با بحث پيرامون آنها، تفاوت بين رنج & ل عارم \\
\hline هدف ارئه مقدمهاى براى تنظيم اهدافى مؤثر مرتبط با ارزشها، مطرح كردن و شناسايى ارزشهاى نوجوانان، تفاوت بين ارزش و & ينجمم \\
\hline 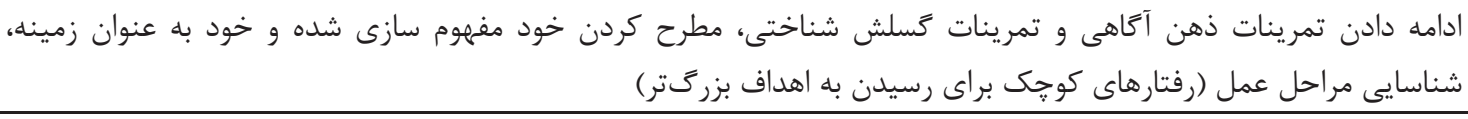 & سشم \\
\hline و تمرينهاى ذهن آَّاهى در حين راه رفتن، شناسايى اهداف رفتار براى رسيدن به ارزشها، الكوريتم همجوشى، ارزيابى، اجتناب & جلسه هفتم \\
\hline تدريجى بودن پيشرش دادن مراجع براى اينكه درمانكً خودش باشكد، تفاوت بين لغزش و بازَشت، عادى سازى سطحى از هيجانات منفى، & سه هشتم \\
\hline
\end{tabular}




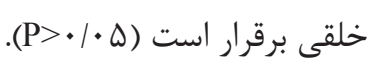

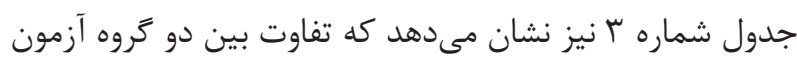

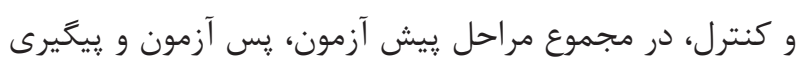

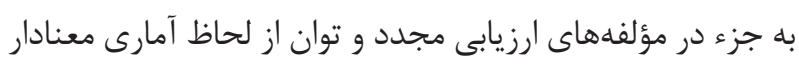

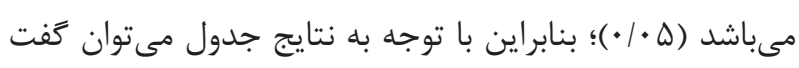

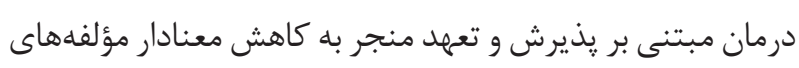

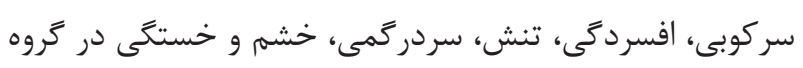

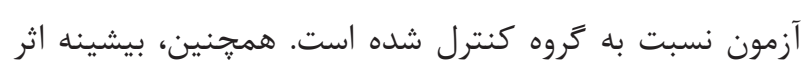

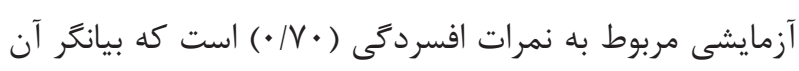

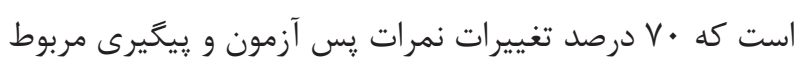

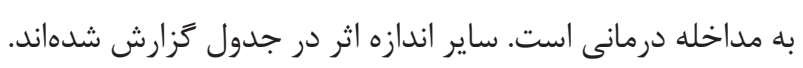

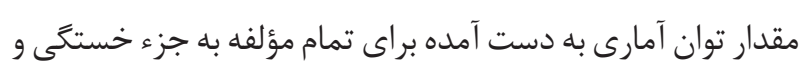

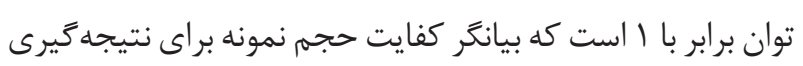

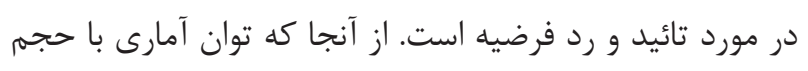

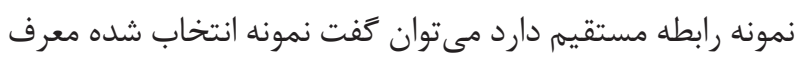

جامعه بوده و امكان تعميم نتايج وجود دارد.

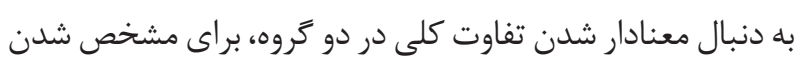

در هايه سوم مشغول به تحصيل بودند. همانطور كه در جدول

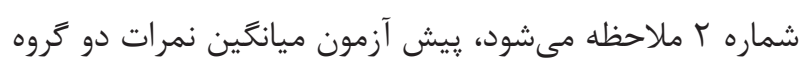

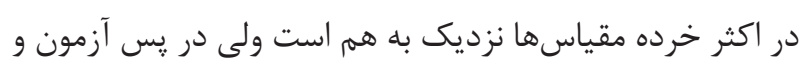

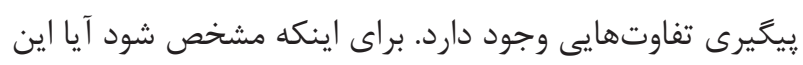

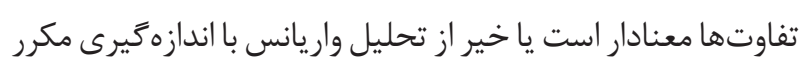
استفاده شد. ابتدا مفروضات روش تحليل كواريانس شامل نرمال

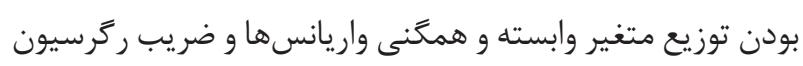
در گروههاى مختلف مورد بررسى قرار ترفت.

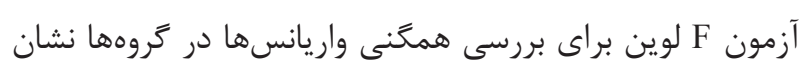

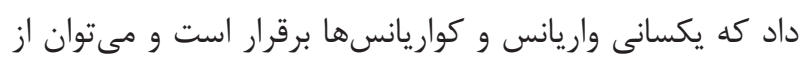

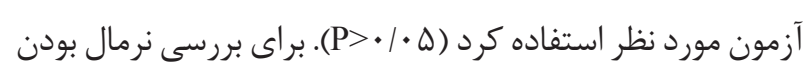
دادهها از آزمون كولموَّوف - اسميرنف استفاده شد؛ كه نتايج

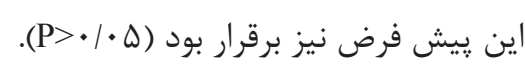

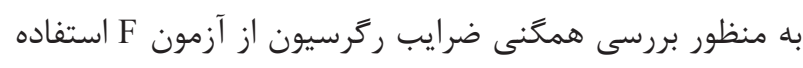

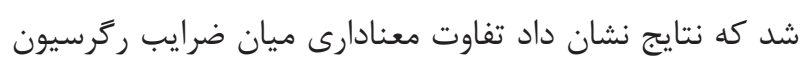

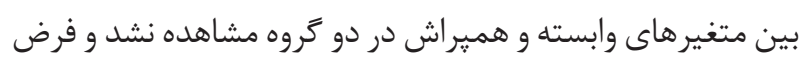

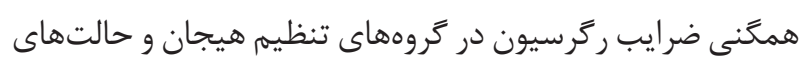

جدول ץ- آمارههاى توصيفى نمرات در كروهها در زير مقياس هاى تنظيم هيجان و حالتهاى خلقى در يِيش آزمون، يس آزمون و پييگيرى

\begin{tabular}{|c|c|c|c|c|c|c|c|}
\hline \multicolumn{2}{|c|}{ ييخيرى } & \multicolumn{2}{|c|}{ يس آزمون } & \multicolumn{2}{|c|}{ يِيش آزمون } & \multirow{2}{*}{ كروه } & \multirow{2}{*}{ متغير } \\
\hline انحراف استاندارد & ميانغين & انحراف استاندارد & ميانگين & انحراف استاندار & ميانگين & & \\
\hline.$/ 11$ & $r / 9 V$ & $\cdot / 1 F$ & $r / 9 V$ &.$/ 14$ & $\mathrm{r} / \Lambda$ & آزمون & \multirow{2}{*}{ ارزيابى مجدد } \\
\hline $.11 \mathrm{r}$ & r/gr & 涪 & $r / \mathcal{E V}$ & $\cdot 111$ & $\Gamma / 10$ & كنترل & \\
\hline .111 & $1 / 94$ & .11 & $1 / V V$ & .119 & $T / V I$ & آزمون & \multirow{2}{*}{ سر كوبى } \\
\hline .11 & $r / 9 \Lambda$ & .1 .9 & $r / 9 \Lambda$ & $\cdot 111$ & $\varphi / \cdot \Delta$ & كنترل & \\
\hline$\cdot / \cdot V \cdot$ & س 1/1 & $\cdot / \cdot \Delta V$ & $1 / 1 \mathrm{VI}$ & $.1 .9 V$ & $r / \cdot T I$ & آزمون & \multirow[b]{2}{*}{ افسردىى } \\
\hline 1.90 & T/VE & . $1 \Delta r$ & T/VE & $.1 .9 r$ & T/VA & كنترل & \\
\hline.$/ 1 T$. & $1 / V r$ & $.|| \Delta \mid$ & $1 / \Delta T$ & $.1 .9 \mathrm{~V}$ & T/VT & آزمون & \multirow[b]{2}{*}{ ت ن } \\
\hline .111 & $r / 9 \Lambda$ &.$/ 1 \mathrm{f}$. & r/৭9 & $.1 \cdot 9$. & r/qF & كنترل & \\
\hline$\cdot 11 \cdot v$ & $1 / 9$. & .1111 & I/TVD & $\cdot 1 \cdot \wedge \Lambda$ & $r / \wedge r$ & آزمون & \multirow[b]{2}{*}{ سردر گمى } \\
\hline $.11 \cdots$ & r/9T & $\cdot 11 \cdot 9$ & $\mathrm{r} / \mathrm{V}$ & $\cdot 1 \cdot 11$ & $r / q$. & كنترل & \\
\hline r & $1 / V$ & $.11 \cdot 9$ & $1 / 4 \Delta$ & $\cdot 11 \cdot r$ & $r / Q$. & آزمون & \multirow[b]{2}{*}{ خشم } \\
\hline$\cdot 11 \cdot f$ & $r / \cdot V$ & $.1 \cdot 91$ & $r / \cdot r$ & .194 & T/AV & كنترل & \\
\hline r & T/TT &.$/ 1 T$. & $r / 99$ & $.|| f \mid$ & $1 / V \Delta$ & آزمون & \multirow[b]{2}{*}{ توان } \\
\hline . Mrt & $r / l \cdot$ & .1111 & $r / l \cdot$ &.$/ 11$ & $r / V T$ & كنترل & \\
\hline$\cdot 1 \cdot 19$ & $r / T \Delta$ & .194 & $T / \mu \Delta$ & $.111 r$ & $r / \wedge \Delta$ & آزمون & \multirow[b]{2}{*}{ خستخى } \\
\hline $.19 r$ & $r / 9$. & $\cdot \mid \wedge \&$ & $r / 9$. & $.1 \cdot 1 \cdot$ & $r / \Delta \Lambda$ & كنترل & \\
\hline
\end{tabular}




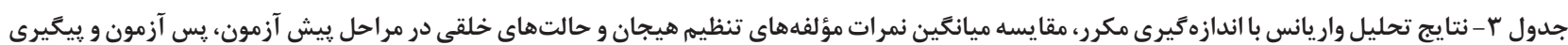

\begin{tabular}{|c|c|c|c|c|c|c|c|c|}
\hline توان آمارى & اندازه اثر & سطح معنادارى & F & ميانگين مجذورات & درجه آزادى & مجموع مجذورات & منبع تغيير & \\
\hline 1 & $\cdot / r \Lambda$ & $\cdot 1 \cdot \cdot 1$ & $9 / \Delta T$ & $r / \cdot F$ & 1 & س & ارزيابى مجدد & \\
\hline \multirow[t]{2}{*}{1} & $.1 \cdot 19$ & .109 & $\cdot / \|^{c} \Delta$ & .1 .91 & 1 & .110 & ارزيابى مجدد" كروه & ارزيابى مجدد \\
\hline & & & & $\cdot|r|$ & rv & $\Lambda / 1 \Delta$ & خطا & \\
\hline 1 & $\cdot / T V$ & $\cdot / \cdot r$ & $9 / \cdot 9$ & r & 1 & $r / V I$ & سر كوبى & \\
\hline \multirow[t]{2}{*}{1} & $\cdot|\pi|$ & $\cdot 1 \cdot 1$ & $9 / 49$ & $t / T \Delta$ & 1 & r/gF & سر كوبى " خروه & سر كوبى \\
\hline & & & & ( & TQ & $9 / \wedge$. & خطا & \\
\hline 1 & $\cdot / \mathrm{V}$ & $.1 \cdot \cdot 1$ & ఎद/TqV & $1 / 9 \Delta V$ & 1 & T/VFI & افسردگى & \\
\hline \multirow[t]{2}{*}{1} & $\cdot 181$ & $\cdot 1 \cdot \cdot 1$ & $\Delta I / \Delta F T$ & $1 / \Delta / F$ & 1 & $r / \Delta \cdot \Delta$ & افسردگى * گروه & افسردگى \\
\hline & & & & $\cdot 1 \cdot r q$ & rq & $1 / 199$ & خطا & \\
\hline 1 & H & $\cdot 1 \cdot \cdot 1$ & IN/DTA & $r / \Delta \Delta \mid$ & $r$ & $\Delta / 1 \cdot r$ & تنش & \\
\hline \multirow[t]{2}{*}{1} & $\cdot / 4 \Delta$ & $\cdot 1 \cdot \cdot 1$ & $r \cdot 119 r$ & r/VAI & r & $\Delta / \Delta \varphi \mid$ & تنش * گروه & تنش \\
\hline & & & &.$/ 1 r \Lambda$ & $\uparrow \wedge$ & $9 / 9 \cdot 9$ & خطا & \\
\hline 1 & .199 & $.1 \cdot \cdot 1$ & $r V / \cdot r q$ & $\Delta / \Delta \Delta \mu$ & 1 & $9 / 9 \Delta V$ & سردرگمى & \\
\hline \multirow[t]{2}{*}{1} & $\cdot|V|$ & $\cdot 1 \cdot \cdot 1$ & $\Delta Q / \Lambda F T$ & $V / \cdot F^{\prime}$ & 1 & $1 \pi / 999$ & سردرگمى: كروه & سردرگمى \\
\hline & & & &.$/ 111$ & pr & $\Delta / \cdot \wedge 1$ & خطا & \\
\hline 1 & $\cdot / \pi \Delta$ & $\cdot 1 \cdot \cdot 1$ & $|r / F \Delta|$ & I/FFT & 1 & $r / 9 \Delta r$ & خشم & \\
\hline \multirow[t]{2}{*}{1} & . & $\cdot 1 \cdot \cdot 1$ & TV/TIY & $7 / 919$ & 1 & $\Delta / \mu G V$ & خشم " گروه & خشم \\
\hline & & & & $\cdot 11 \cdot V$ & pF & F/VMr & خطا & \\
\hline 1 & .10 & $\cdot / T \Lambda$ & I/TVF & •r & 1 & $\cdot 10 \cdot r$ & توان & \\
\hline \multirow[t]{2}{*}{1} & $\cdot / 4 V$ & $\cdot 1 \cdot \cdot 1$ & rI/911 & $\Delta / T / 1$ & 1 & $N|9 V|$ & توان * زروه & توان \\
\hline & & & & $\cdot / T V H$ & ५q & $q / 4 \& F$ & خطا & \\
\hline . IAT & .111 & $\cdot 1 \cdot r$ & $\Delta / T \& V$ & $\cdot / 4 \cdot 1$ & 1 & . $/ \Delta F T$ & خستكى & \\
\hline \multirow[t]{2}{*}{.191} & .179 & $\cdot 1 \cdot \cdot 1$ & $1 \cdot 11 \cdot f$ & . IVAT & 1 & $1 / \cdot r q$ & خستخى " خروه & خستخى \\
\hline & & & & $\cdot / \cdot V V$ & ו & $r / 4 \in \Lambda$ & خطا & \\
\hline
\end{tabular}

جدول F - آزمون تعقيبى بونفرونى براى مقايسه ميانغين نمرات مقياسهاى تنظيم هيجان و حالتهاى خلقى

\begin{tabular}{|c|c|c|c|}
\hline سطح معنادارى & اختلاف ميانَين يس آزمون و بيخَيرى & اختلاف ميانغين يِش آزمون و يس آزمون & مقياس \\
\hline$\cdot 1 \cdot \Delta$ & - . MTt &.$- / 4 q V$ & سركوبى \\
\hline$\cdot 1 \cdot \Delta$ & $-\cdot / T \Delta \mid$ & $-\cdot / F^{\prime} T F$ & افسردگى \\
\hline$\cdot 1 \cdot \Delta$ & $-\cdot / \mathcal{F} \wedge$. & $-\cdot 109 \mid$ & تنش \\
\hline$\cdot 1 \cdot \Delta$ & - . /Var & $-V \Delta G$ & سردر گمى \\
\hline$\cdot 1 \cdot \Delta$ & $-r 91$ & - FEA & خشم \\
\hline$\cdot 1 \cdot \Delta$ & | & $-\cdot / T \cdot r$ & خستخى \\
\hline
\end{tabular}

با توجه به جدول شماره \& نتايج نشان داد تفاوت بين ميانگين نمرات

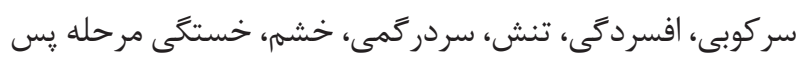

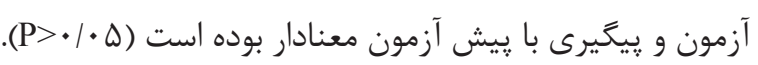

اينكه تفاوت بين كدام ميانخين معنادار است از آزمون مقايسهاى

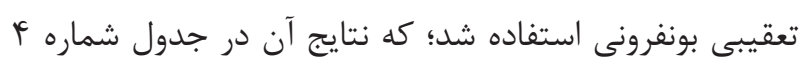
ارائه شده است. 
برانكيختكى فيزيولوزى همراه است. در فرآيند درمان ACT به

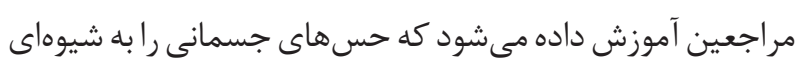

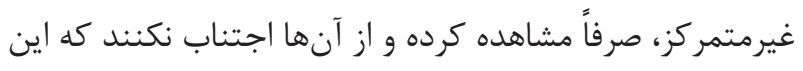

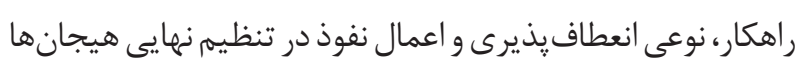

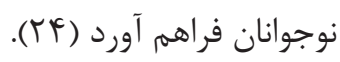

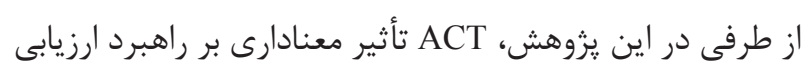

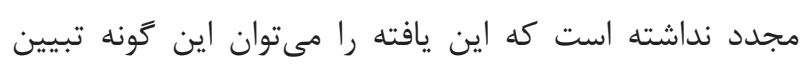

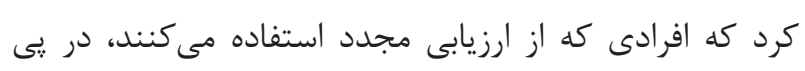

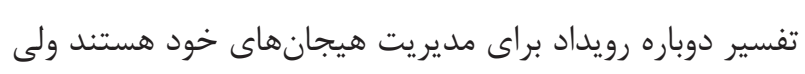
تكنيكهاى ACT نظير گسلش شناختى و ذهن آكاهى به مراجع

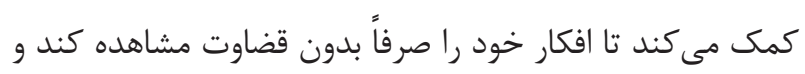

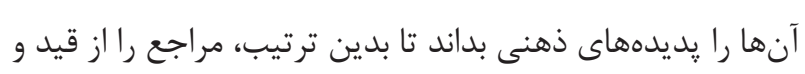
بندهاى رفتارى اين افكار رها سازند (F) أ ( ).

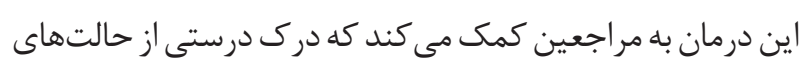

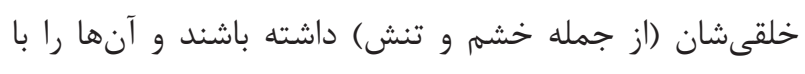

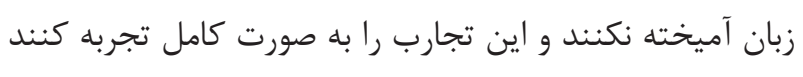

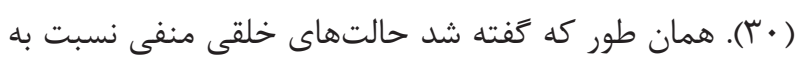

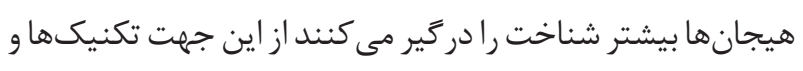

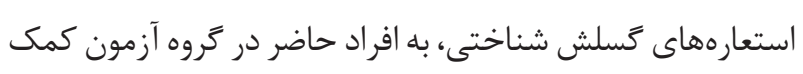
كرد كه به جاى تغيير دادن شكل و محتواى افكار، كاركردهاى

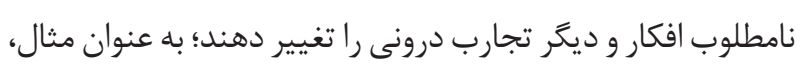

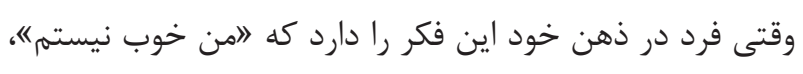

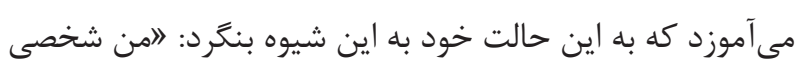
هستم كه فكر مى كند خوب نيستها. هدف فرايند كسلش در در

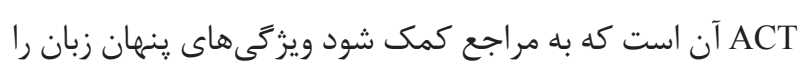

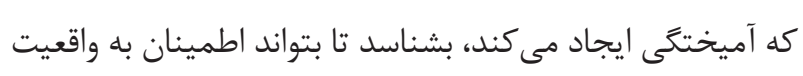

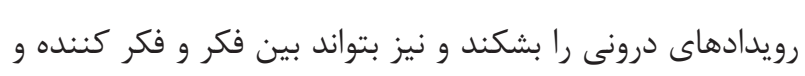

احساس و احساس كننده فاصله ايجاد كند (إr).

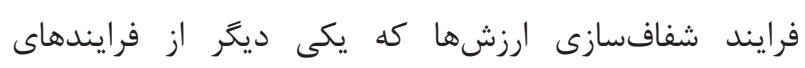

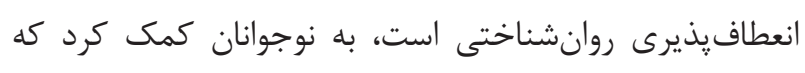

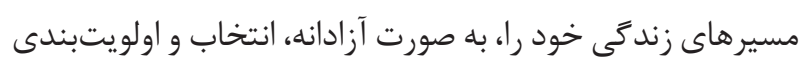

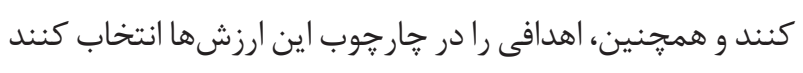

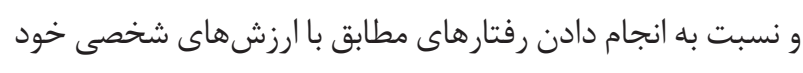

\section{بحث و نتيجه كيرى}

هدف از انجام يزوهش حاضر، بررسى تأثير آموزش كروهى درئي دمان

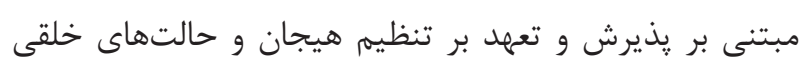

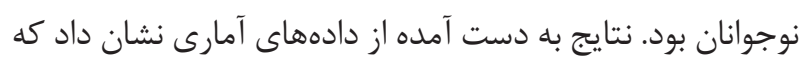

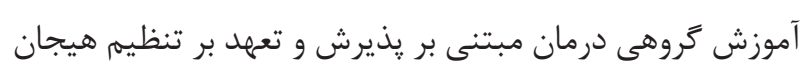

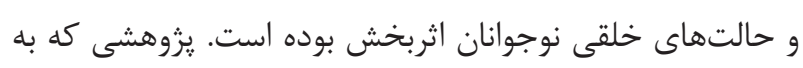
بررسى اثربخشى آموزش ACT بر تنظيم هيجان و حالتهان اتربخد بوده

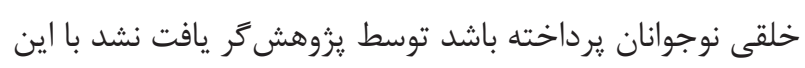

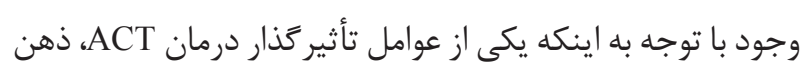

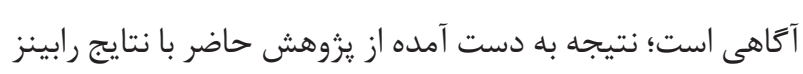

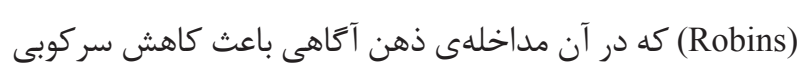

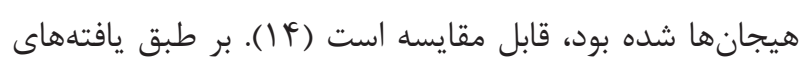

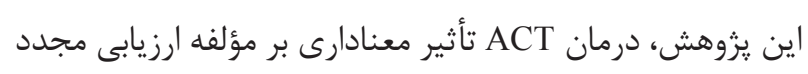
نداشته، اين يافته بانتايج يزوهش كيانى و همكاران كه در آن درمان

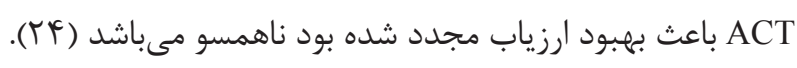

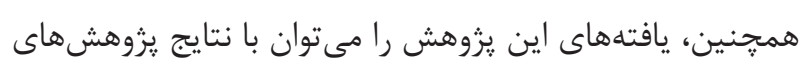

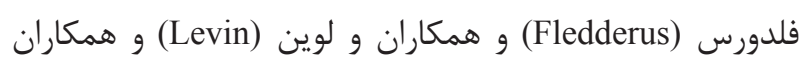

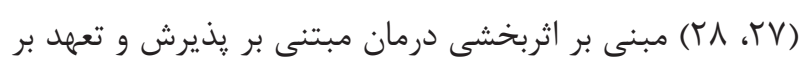

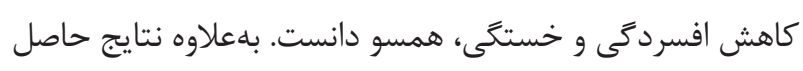

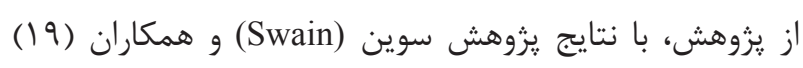
كه اثربخشى اين درمان را بر اضطراب كودكان و نوجوانان تائيد

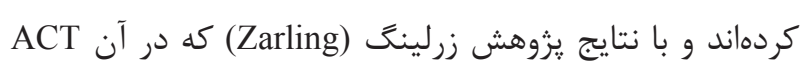

باعث كاهش يرخاشكرى شده بود، همسو است (9) (Y).

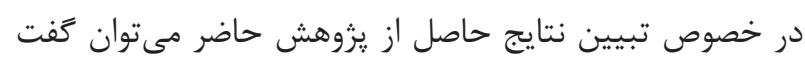

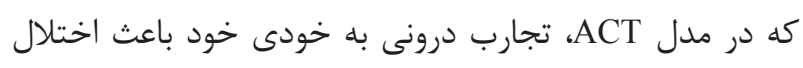

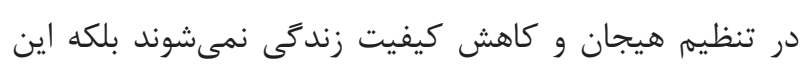

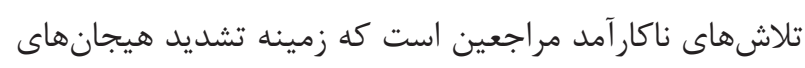

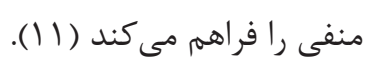
در اين رابطه، درمان ACT با تكنيك ناميدى خلاقانه تلاشهيد (1).

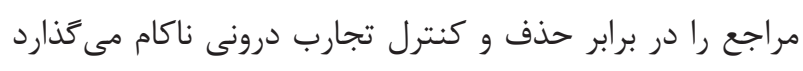

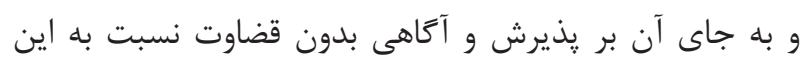

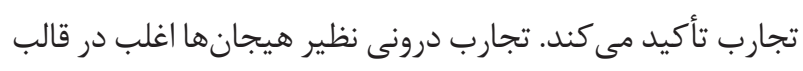

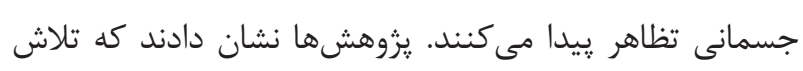

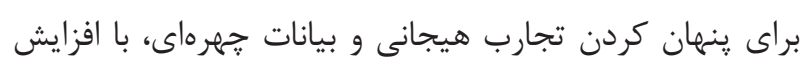




\section{تشكر و قدردانى}

اين مقاله حاصل پايان كارشناسى ارشد روان شناسى بالينى دانشعاه

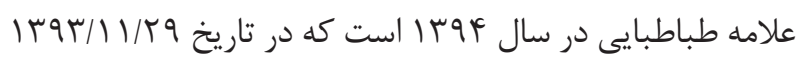
با شماره | بدين وسيله از همكارى تمامى شركت كنندكان در اين مطالعه و مسئولين كانون صادق الوعد تهران تشكر و قدردانى مىشود.

تضاد منافع

هيج گَونه تضاد منافع در اين مطالعه بين يزوهشگران و نويسندكان مقاله وجود نداشت.

\section{References}

1- Zhang Y, Zhang X, Zhang L, Guo C. Executive Function and Resilience as Mediators of Adolescents' Perceived Stressful Life Events and School Adjustment. Front Psychol. 2019;10:446. http://dx.doi.org/10.3389/fpsyg.2019.00446 www.ncbi.nlm.nih. gov/pubmed/30873099

2- McLaughlin KA, Hatzenbuehler ML, Mennin DS, NolenHoeksema S. Emotion dysregulation and adolescent psychopathology: a prospective study. Behav Res Ther. 2011;49(9):544-54. http://dx.doi.org/10.1016/j.brat.2011.06.003 www.ncbi.nlm.nih.gov/pubmed/21718967

3- Klemanski DH, Curtiss J, McLaughlin KA, Nolen-Hoeksema S. Emotion Regulation and the Transdiagnostic Role of Repetitive Negative Thinking in Adolescents with Social Anxiety and Depression. Cognit Ther Res. 2017;41(2):206-19. http://dx.doi. org/10.1007/s10608-016-9817-6 www.ncbi.nlm.nih.gov/ pubmed/28579659

4- Rathi N, Rastogi R. Assessing the relationship between emotional intelligence, occupational self-efficacy and organizational commitment. J Indian Academy of Applied Psychology. 2009;35(1):93-102.

5- Thompson RA. Emotional regulation and emotional development. Educational Psychology Review. 1991;3(4):269-307. http:// dx.doi.org/10.1007/bf01319934

6- Brockman R, Ciarrochi J, Parker P, Kashdan T. Emotion regulation strategies in daily life: mindfulness, cognitive reappraisal and emotion suppression. Cogn Behav Ther. 2017;46(2):91-113. http:// dx.doi.org/10.1080/16506073.2016.1218926 www.ncbi.nlm.nih. gov/pubmed/27684649

7- Beedie CJ, Terry PC, Lane AM, Devonport TJ. Differential assessment of emotions and moods: Development and validation of the Emotion and Mood Components of Anxiety Questionnaire. Personality and Individual Differences. 2011;50(2):228-33. http:// dx.doi.org/10.1016/j.paid.2010.09.034

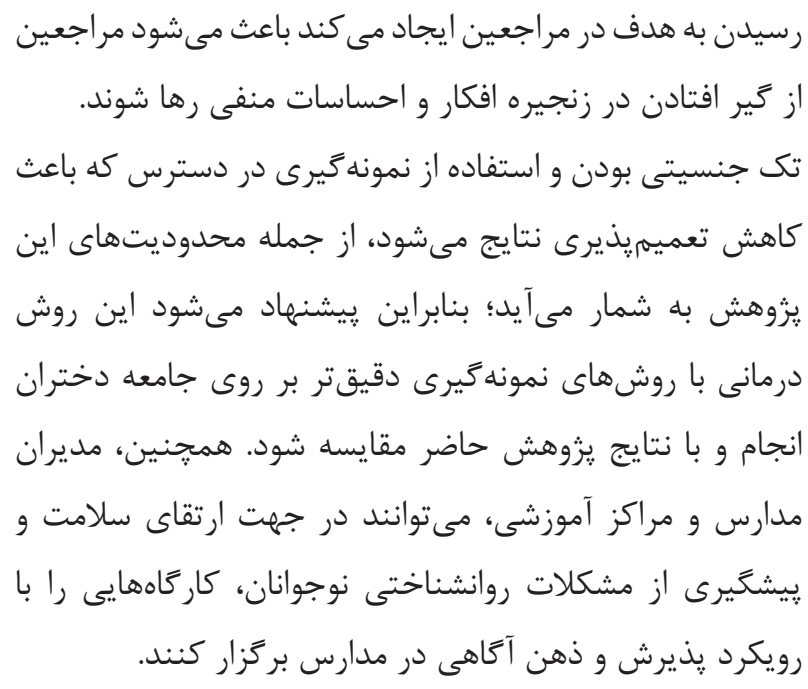

8- Pico-Perez M, Radua J, Steward T, Menchon JM, SorianoMas C. Emotion regulation in mood and anxiety disorders: A meta-analysis of fMRI cognitive reappraisal studies. Prog Neuropsychopharmacol Biol Psychiatry. 2017;79(Pt B):96-104. http://dx.doi.org/10.1016/j.pnpbp.2017.06.001 www.ncbi.nlm. nih.gov/pubmed/28579400

9- Beauregard M, Lévesque J, Paquette V. 6. Neural basis of conscious and voluntary self-regulation of emotion. Consciousness, Emotional Self-Regulation and the Brain. Advances in Consciousness Research2004.

10- Eifert GH, Forsyth JP, Arch J, Espejo E, Keller M, Langer D. Acceptance and Commitment Therapy for Anxiety Disorders: Three Case Studies Exemplifying a Unified Treatment Protocol. Cognitive and Behavioral Practice. 2009;16(4):368-85. http:// dx.doi.org/10.1016/j.cbpra.2009.06.001

11- Hayes SC, Strosahl K, Wilson KG, Bissett RT, Pistorello J, Toarmino D, et al. Measuring experiential avoidance: A preliminary test of a working model. The Psychological Record. 2017;54(4):553-78. http://dx.doi.org/10.1007/bf03395492

12- Hoffmann AN, Contreras BP, Clay CJ, Twohig MP. Acceptance and Commitment Therapy for Individuals with Disabilities: A Behavior Analytic Strategy for Addressing Private Events in Challenging Behavior. Behav Anal Pract. 2016;9(1):14-24. http:// dx.doi.org/10.1007/s40617-016-0105-4 www.ncbi.nlm.nih.gov/ pubmed/27606236

13- Liverant GI, Brown TA, Barlow DH, Roemer L. Emotion regulation in unipolar depression: the effects of acceptance and suppression of subjective emotional experience on the intensity and duration of sadness and negative affect. Behav Res Ther. 2008;46(11):1201-9. http://dx.doi.org/10.1016/j.brat.2008.08.001 www.ncbi.nlm.nih.gov/pubmed/18828992

14- Robins CJ, Keng SL, Ekblad AG, Brantley JG. Effects of mindfulness-based stress reduction on emotional experience 
and expression: a randomized controlled trial. J Clin Psychol. 2012;68(1):117-31. http://dx.doi.org/10.1002/jclp.20857 www. ncbi.nlm.nih.gov/pubmed/22144347

15- Livheim F, Hayes L, Ghaderi A, Magnusdottir T, Högfeldt A, Rowse J, et al. The Effectiveness of Acceptance and Commitment Therapy for Adolescent Mental Health: Swedish and Australian Pilot Outcomes. Journal of Child and Family Studies. 2014;24(4):1016-30. http://dx.doi.org/10.1007/s10826-014-99129

16- Hayes L, Boyd CP, Sewell J. Acceptance and Commitment Therapy for the Treatment of Adolescent Depression: A Pilot Study in a Psychiatric Outpatient Setting. Mindfulness. 2011;2(2):86-94. http://dx.doi.org/10.1007/s12671-011-0046-5

17- Twohig MP, Levin ME. Acceptance and Commitment Therapy as a Treatment for Anxiety and Depression: A Review. Psychiatr Clin North Am. 2017;40(4):751-70. http://dx.doi.org/10.1016/j. psc.2017.08.009 www.ncbi.nlm.nih.gov/pubmed/29080598

18- Heydari M, Masafi S, Jafari M, Saadat SH, Shahyad S. Effectiveness of Acceptance and Commitment Therapy on Anxiety and Depression of Razi Psychiatric Center Staff. Open Access Maced J Med Sci. 2018;6(2):410-5. http://dx.doi.org/10.3889/ oamjms.2018.064 www.ncbi.nlm.nih.gov/pubmed/29531615

19- Swain J, Hancock K, Dixon A, Koo S, Bowman J. Acceptance and commitment therapy for anxious children and adolescents: study protocol for a randomized controlled trial. Trials. 2013;14:140. http://dx.doi.org/10.1186/1745-6215-14-140 www.ncbi.nlm.nih. gov/pubmed/23672442

20- Kelson J, Rollin A, Ridout B, Campbell A. Internet-Delivered Acceptance and Commitment Therapy for Anxiety Treatment: Systematic Review. J Med Internet Res. 2019;21(1):e12530. http://dx.doi.org/10.2196/12530 www.ncbi.nlm.nih.gov/ pubmed/30694201

21- Rajabi S, Yazdkhasti F. The effectiveness of acceptance and commitment group therapy on anxiety and depression in women with MS who were referred to the MS association. J Clin Psychol. 2014;6(1):29-40.

22- Gross JJ, John OP. Individual differences in two emotion regulation processes: implications for affect, relationships, and well-being. J Pers Soc Psychol. 2003;85(2):348-62. http:// dx.doi.org/10.1037/0022-3514.85.2.348 www.ncbi.nlm.nih.gov/ pubmed/12916575

23- Balzarotti S, John OP, Gross JJ. An Italian adaptation of the emotion regulation questionnaire. European Journal of Psychological Assessment. 2010. http://dx.doi.org/10.1037/t03783-000

24- Kiani A, Ghasemi N, Pourabbas A. The comparsion of the efficacy of group psychotherapy based on acceptance and commitment therapy, and mindfulness on craving and cognitive emotion regulation in methamphetamine addicts. Research on addiction. 2013;6(24):27-36.

25- Terry PC, Lane AM, Fogarty GJ. Construct validity of the Profile of Mood States - Adolescents for use with adults. Psychology of Sport and Exercise. 2003;4(2):125-39. http://dx.doi.org/10.1016/ s1469-0292(01)00035-8

26- Farrokhi A, Aghasi BS, Motesharee E, Farahani A. The Relationship and Comparison between Perfectionism andMood States of Team and Individual Sports Athletes. 2012.

27- Fledderus M, Bohlmeijer ET, Pieterse ME, Schreurs KM. Acceptance and commitment therapy as guided self-help for psychological distress and positive mental health: a randomized controlled trial. Psychol Med. 2012;42(3):485-95. http://dx.doi. org/10.1017/S0033291711001206 www.ncbi.nlm.nih.gov/ pubmed/21740624

28- Levin ME, Haeger JA, Pierce BG, Twohig MP. Web-Based Acceptance and Commitment Therapy for Mental Health Problems in College Students: A Randomized Controlled Trial. Behav Modif. 2017;41(1):141-62. http://dx.doi.org/10.1177/0145445516659645 www.ncbi.nlm.nih.gov/pubmed/27440189

29- Zarling A, Lawrence E, Marchman J. A randomized controlled trial of acceptance and commitment therapy for aggressive behavior. J Consult Clin Psychol. 2015;83(1):199-212. http://dx.doi. org/10.1037/a0037946 www.ncbi.nlm.nih.gov/pubmed/25265545

30- Zhang CQ, Leeming E, Smith P, Chung PK, Hagger MS, Hayes SC. Acceptance and Commitment Therapy for Health Behavior Change: A Contextually-Driven Approach. Front Psychol. 2017;8:2350. http://dx.doi.org/10.3389/fpsyg.2017.02350 www. ncbi.nlm.nih.gov/pubmed/29375451

31- Hayes SC, Luoma JB, Bond FW, Masuda A, Lillis J. Acceptance and commitment therapy: model, processes and outcomes. Behav Res Ther. 2006;44(1):1-25. http://dx.doi.org/10.1016/j. brat.2005.06.006 www.ncbi.nlm.nih.gov/pubmed/16300724 